\title{
Effect of CD38 on the multidrug resistance of human chronic myelogenous leukemia K562 cells to doxorubicin
}

\author{
LEMAN YALÇINTEPE, EMRE HALIS and SIBEL ULKU
}

\author{
Department of Biophysics, Istanbul Faculty of Medicine, Istanbul University, Çapa-Istanbul, Istanbul 34093, Turkey
}

Received March 17, 2015; Accepted December 14, 2015

DOI: $10.3892 / 01.2016 .4165$

\begin{abstract}
Drug resistance is a serious challenge in cancer chemotherapy. Alterations in the intracellular concentration and homeostasis of calcium $\left(\mathrm{Ca}^{2+}\right)$ may contribute to the development of drug resistance. To investigate the mechanism of drug resistance in leukemia, the present study rendered human chronic myelogenous leukemia K562 cells resistant to the cytotoxic effect of doxorubicin by progressively adapting the sensitive parental K562 cells to doxorubicin. The resulting cells were termed K562/DOX. Subsequently, the expression of two multidrug resistance proteins, P-glycoprotein (P-gp) and multidrug resistance protein 1 (MRP1), was analyzed in K562/DOX cells. In addition to P-gp and MRP1, these cells also expressed cluster of differentiation (CD)38 and its active enzyme adenosine diphosphate (ADP)-ribosyl cyclase. The present study also demonstrated that K562/DOX cells responded to cyclic ADP-ribose-mediated increases in intracellular $\mathrm{Ca}^{2+}$. These data indicate that $\mathrm{CD} 38$ may participate in the development of drug resistance to doxorubicin in K562 cells.
\end{abstract}

\section{Introduction}

Cytostatic drug resistance in cancer cells is defined as multidrug resistance (1). One of the main mechanisms of drug resistance in cancer cells is the activation of adenosine triphosphate(ATP)-dependent transporters, which increase the transmembrane efflux of drugs from cells, thus decreasing the drug concentration in the cytoplasm. Consequently, the cell becomes insensitive to the effect of cytostatic drugs (2). The ATP-binding cassette (ABC) family is a ubiquitous and important family of ATP-dependent transporters $(3,4)$. Although the mechanisms of resistance that affect the ATP-dependent transporter pathways are not fully elucidated at the molecular level, P-glycoprotein (P-gp) and multidrug resistance protein 1

Correspondence to: Professor Leman Yalçintepe, Department of Biophysics, Istanbul Faculty of Medicine, Istanbul University, Millet Street, Çapa-Istanbul, Istanbul 34093, Turkey

E-mail: lemany@istanbul.edu.tr

Key words: multidrug resistance, doxorubicin, P-glycoprotein, ADP-ribosyl cyclase, CD38
(MRP1) are the most important and widely studied members of the ABC family (5). P-gp is the protein product of multidrug resistance gene 1 (MDR1), and acts as a drug efflux pump in cells. P-gp is dependent on two molecules of ATP as an energy source to export numerous structurally unrelated chemotherapeutic drugs from the cell to the outside (3). In cells that express increased levels of P-gp, intracellular drug levels are decreased, which is associated with a decrease in cytotoxicity (6). Therefore, novel studies on ATP-dependent transporter pathways may contribute to preventing drug resistance in cancer.

Cluster of differentiation (CD)38, a 45-kDa antigen present in the surface of human cells, is a type II transmembrane glycoprotein that has a short $\mathrm{N}$-terminal cytoplasmic domain and a long C-terminal extracellular domain (7). The expression of CD38 is used as a phenotypic marker for the differentiation and activation of $\mathrm{T}$ and $\mathrm{B}$ lymphocytes (7-9), in addition to other types of cells such as erythrocytes (10). CD38 has been demonstrated to be a bifunctional enzyme with nicotinamide adenine dinucleotide (NAD) ${ }^{+}$-glycohydrolase (NADase) and adenosine diphosphate (ADP)-ribosyl cyclase activities $(11,12)$. The resulting product of its cyclase activity, cyclic ADP-ribose (cADPR), has become the focus of several studies due to its role as an inositol 1,4,5-trisphosphate-independent calcium $\left(\mathrm{Ca}^{+2}\right)$ mobilizer $(13,14)$. Furthermore, CD38 has been revealed to catalyze a base exchange reaction in which (NAD) phosphate in the presence of nicotinic acid is converted to nicotinic acid adenine dinucleotide phosphate, which is a $\mathrm{Ca}^{+2}$ mobilizer (15-17). $\mathrm{Ca}^{2+}$ acts as a second messenger in the regulation of signal transduction pathways by modulating kinase activities in numerous cells (18). Controlled increases in the intracellular levels of $\mathrm{Ca}^{2+}$ through the action of $\mathrm{Ca}^{+2}$ pumps, ion channels and $\mathrm{Ca}^{+2}$ buffering proteins, are important in the regulation of normal cellular function and cell apoptosis (19). Therefore, the cytotoxic effects of certain drugs used to treat cancer may occur as a result of an increase in the intracellular concentration of $\mathrm{Ca}^{2+}(20,21)$.

The present study investigated a doxorubicin-resistant human chronic myelogenous leukemia (CML) K562 cell line as a model system to evaluate the potential role of CD38 in the development of drug resistance. The results demonstrated that MRP1 and, in particular, P-gp mediated multidrug resistance in these cells. K562 cells that were resistant to doxorubicin expressed high levels of CD38, which was associated with a transient increase in the levels of cADPR and intracellular 
$\mathrm{Ca}^{2+}$ concentration. The effect of specific inhibitors for P-gp (verapamil) and MRP1 (MK-571) on the cADPR-mediated release of $\mathrm{Ca}^{2+}$ failed to inhibit the response of cells to cADPR.

\section{Materials and methods}

Cell lines and development of a resistant subline. Human CML K562 cells were maintained in Dulbecco's modified Eagle's medium: Nutrient Mixture F-12 (Thermo Fisher Scientific, Inc., Waltham, MA, USA) supplemented with $10 \%$ heat-inactivated fetal calf serum (FCS; Gibco; Thermo Fisher Scientific, Inc.), L-glutamine (Gibco; Thermo Fisher Scientific, Inc.) and antibiotics (penicillin/streptomycin; Stemcell Technologies, Inc., Vancouver, BC, Canada). The cells were incubated at $37^{\circ} \mathrm{C}$ in a humidified atmosphere of $5 \% \mathrm{CO}_{2}$ in a Heraeus ${ }^{\circledR}$ incubator (Thermo Fisher Scientific, Inc.). Doxorubicin (Sigma-Aldrich, St. Louis, MO, USA) was applied to the parental K562 cells in dose increments between $0.1 \mu \mathrm{M}$ and $1.4 \mu \mathrm{M}$ to develop the doxorubicin-resistant subline K562/DOX. The adapted cells were allowed to become confluent in the presence of the corresponding concentration of drug, and were maintained under those conditions for 3-4 weeks). Cells that had been selected with $1.4 \mu \mathrm{M}$ doxorubicin were maintained in medium supplemented with 1.4 $\mu \mathrm{M}$ doxorubicin for subsequent assays.

Flow cytometry analysis of P-gp, MRPI and CD38. K562 and K562/DOX cells were centrifuged at 1,500 $\mathrm{x} g$ and suspended at a cell density of $1 \times 10^{6}$ cells $/ \mathrm{ml}$ in cold phosphate-buffered saline (PBS) prior to be stained for $30 \mathrm{~min}$ at $4^{\circ} \mathrm{C}$ with the following monoclonal antibodies: Mouse immunoglobulin (Ig) G anti-human anti-CD38 conjugated to allophycocyanin (dilution, 1:200 in PBS; catalog no, 340439; BD Biosciences, San Jose, CA, USA), monoclonal mouse anti-human anti-P-gp conjugated to phycoerythrin (dilution, 1:100 in PBS; catalog no. 557003; BD Biosciences) and mouse IgG anti-human anti-MRP1 conjugated to fluorescein isothiocyanate (dilution, 1:100 in PBS; catalog no., 557593; BD Biosciences). Subsequently, the cells were washed with PBS (BD Biosciences), centrifuged at $1,500 \mathrm{x}$ g for $5 \mathrm{~min}$ and analyzed using $\mathrm{BD}$ FACSAria II ${ }^{\mathrm{TM}}$ flow cytometer and BD CellQuest ${ }^{\mathrm{TM}}$ (BD Biosciences). Gates were set up to exclude nonviable cells and debris. The negative fraction was determined using appropriate isotype controls.

Rhodamine (Rho)-123 efflux assay. P-gp activity was determined using Rho-123 (Sigma-Aldrich) as a marker of P-gp efflux, since Rho-123 is a fluorescent dye and a substrate for P-gp (22). K562 and K562/DOX cells ( $1 \times 10^{6}$ cells $\left./ \mathrm{ml}\right)$ were incubated with $2 \mu \mathrm{g} / \mathrm{ml}$ Rho-123 in the presence or absence of the P-gp inhibitor verapamil (20 $\mu \mathrm{g} / \mathrm{ml}$; Sigma-Aldrich) for $30 \mathrm{~min}$ at $37^{\circ} \mathrm{C}$ in a humidified atmosphere of $5 \% \mathrm{CO}_{2}$. Upon washing with PBS, the cells were incubated for $1 \mathrm{~h}$ in Rho-123-free medium supplemented with $10 \%$ FCS, in the presence or absence of verapamil. Finally, the cells were analyzed using BD FACSAria II flow cytometer.

cADPR activity assay. cADPR activity was evaluated using nicotinamide guanine dinucleotide (NGD+; Sigma-Aldrich) as a substrate, and measuring the production of cyclic guanosine diphosphate-ribose (cGDPR) as an increase in fluorescence.
cGDPR, the guanine nucleotide equivalent to cADPR, is resistant to hydrolysis, in contrast to cADPR (23) and is also fluorescent, which allows continuous monitoring of the reac-

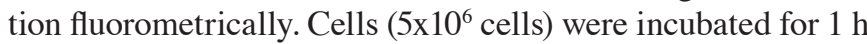
at $37^{\circ} \mathrm{C}$ in $1.5 \mathrm{ml} \mathrm{PBS} \mathrm{containing} 50 \mu \mathrm{M} \mathrm{NGD}^{+}$and $20 \mathrm{mM}$ Tris-hydrochloride ( $\mathrm{pH}, 7.4$; Sigma-Aldrich). The excitation wavelength was set at $300 \mathrm{~nm}$, and the emission was measured at $410 \mathrm{~nm}$ using LS 45 Fluorescence Spectrometer (PerkinElmer, Inc., Waltham, MA, USA). The quantity of cGDPR produced was determined by comparing the fluorescence intensity of the sample with that of the cGDPR standards (24).

Western blotting of CD38. K562 and K562/DOX cells were harvested, and equal amounts of cell lysate proteins were analyzed using $10 \%$ sodium dodecyl sulfate-polyacrylamide gel electrophoresis (SDS-PAGE; acrylamide, Sigma-Aldrich; bisacrylamide, Amresco, Solon, OH, USA; Tris, Sigma-Aldrich; TEMED, Sigma-Aldrich; ammonium persulfate, Sigma-Aldrich), as previously described (25). Briefly, equal amounts $(10 \mu \mathrm{g})$ of cell lysate were loaded onto SDS-PAGE gels using the Mini-PROTEAN ${ }^{\circledR}$ Electrophoresis System (Bio-Rad Laboratories, Inc., Hercules, CA, USA). Proteins were next transferred electrophoretically onto nitrocellulose membranes. The membranes were blocked for $1 \mathrm{~h}$ at room temperature or overnight at $4^{\circ} \mathrm{C}$ with Tris-buffered saline and Tween 20 (TBST; $50 \mathrm{mM}$ Tris, ph 7.6; $150 \mathrm{mM}$ $\mathrm{NcCl}$, Honeywell Specialty Chemicals, Seelze, Germany; $0.1 \%$ Tween-20, Honeywell Specialty Chemicals) containing $3 \%$ bovine serum albumin, followed by incubation with anti-CD38 monoclonal antibody (catalog no, OKT10; Santa Cruz Biotechnology, Inc., Dallas, TX, USA) and anti-P-gp antibody (catalogue number D11; Santa Cruz Biotechnology, Inc.) in $3 \%$ bovine serum albumin overnight at $4^{\circ} \mathrm{C}$ or for $2 \mathrm{~h}$ at room temperature. Following incubation, the membranes were washed 3 times with TBST. Detection of the primary antibodies was achieved by incubation with alkaline phosphatase-conjugated bovine anti-goat antibody for $1 \mathrm{~h}$ at room temperature (dilution 1:1,000 in 3\% TBST; catalog no., Sc-2381; Santa Cruz Biotechnology, Inc., Dallas, TX, USA), followed by 3 washes with TBST. Alkaline phosphatase activity was detected using 5-bromo-4-chloro-3'-indolyl phosphate/nitro-blue tetrazolium as a substrate (Promega Corp., Madison, WI, USA) for colorimetric detection.

$\mathrm{Ca}^{2+}$ release. To determine $\mathrm{Ca}^{2+}$ release, $3 \times 10^{6}$ cells were rinsed with Hank's Balanced Salt Solution (HBSS; Gibco; Thermo Fisher Scientific, Inc.). Subsequently, $0.5 \mathrm{ml}$ of $5 \mu \mathrm{M}$ Fura-2 acetoxymethyl ester (AM; Sigma-Aldrich) dissolved in HBSS [stock solution, $1.5 \mathrm{mM}$ in dimethyl sulfoxide (AppliChem GmbH; Darmstadt, Germany) containing 20\% Pluronic ${ }^{\circledR}$ F-127 (Sigma-Aldrich)] was added to the cells for $30 \mathrm{~min}$ at room temperature. Upon rinsing the cells twice with HBSS, LS 45 Fluorescence Spectrometer was used for the fluorometric measurement of $\mathrm{Ca}^{2+}$ (excitation wavelengths, 340 and $380 \mathrm{~nm}$; emission wavelength, $510 \mathrm{~nm}$ ). Maximum and minimum fluorescence ratios ( $\mathrm{Rmax}$ and $\mathrm{Rmin}$, respectively) were obtained by the addition of $10 \mu \mathrm{M}$ ionomycin (EMD Millipore, Billerica, MA, USA) and $4 \mathrm{mM}$ ethylene glycol tetraacetic acid (Sigma-Aldrich). 8-bromo-cADPR is a specific antagonist of cADPR. It was used at a $100 \mu \mathrm{M}$ 

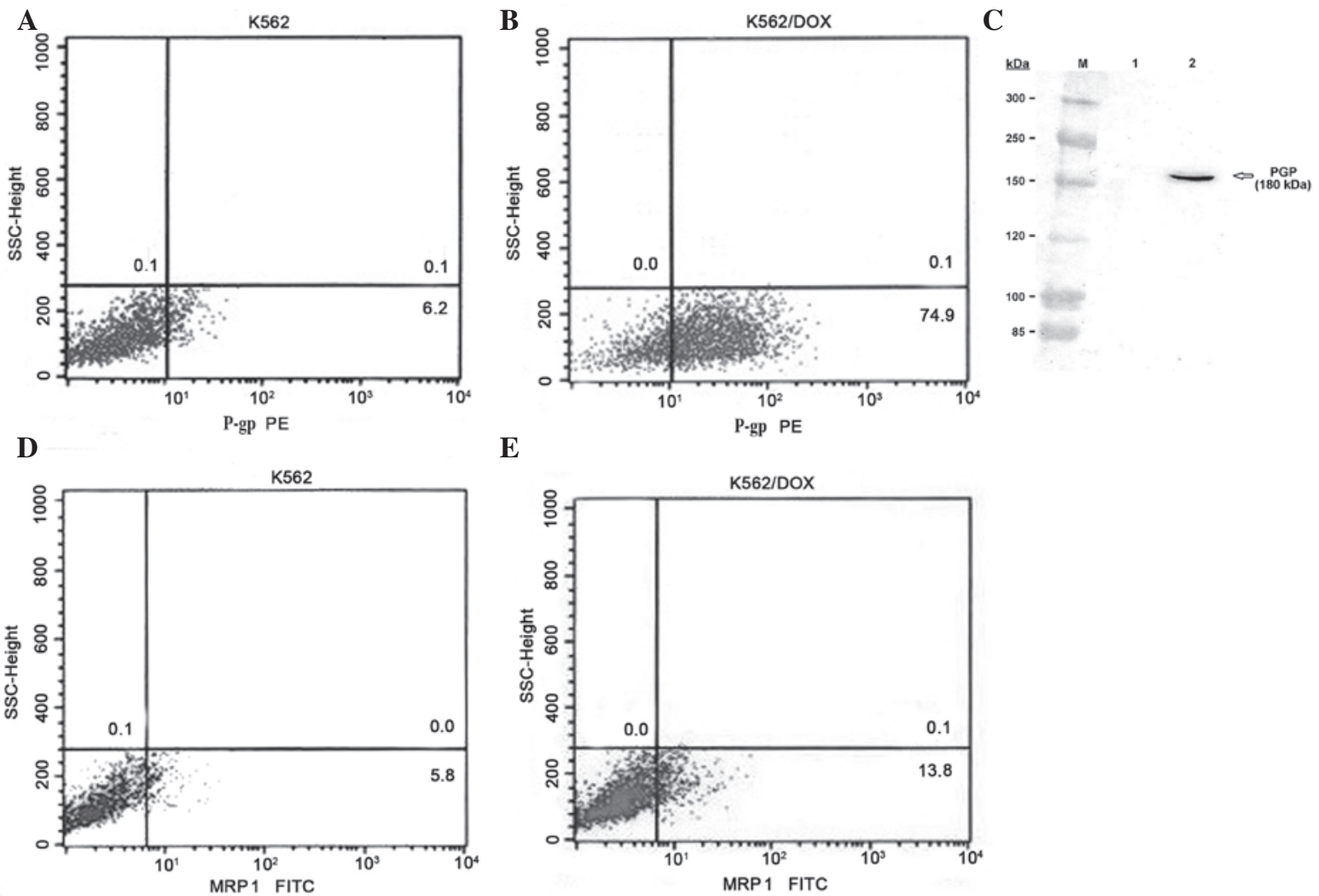

Figure 1. Expression of P-gp and MRP1 in human chronic myelogenous leukemia K562 and K562/DOX cells. Analysis of the expression of P-gp in (A) K562 and (B) K562/DOX cells using flow cytometry. (C) Western blot detection of the protein levels of P-gp present in cell lysates of K562 (Lane 1) and K562/DOX (Lane 2) cells. Similar blots were obtained from three independent experiments. Analysis of the expression of MRP1 in (D) K562 and (E) K562/DOX cells using flow cytometry. K562/DOX, human chronic myelogenous leukemia K562 doxorubicin-resistant subline; P-gp, P-glycoprotein; MRP1, multidrug resistance protein 1; PE, phycoerythrin; FITC, fluorescein isothiocyanate; SSC, side-scattered light.

concentration (Sigma-Aldrich). Thapsigargin is potent endomembrane $\mathrm{Ca}^{2+}$-ATPase inhibitor, which can release $\mathrm{Ca}^{2+}$ from intacellular stores. It was used at $1 \mu \mathrm{M}$ concentration (Sigma-Aldrich). The fluorescence signal was calibrated using the Grynkiewicz equation (26).

Statistical analysis. Statistical significance between control conditions and each of the exposure samples was calculated with Student's $t$ test, using SPSS version 21 software (IBM SPSS, Armonk, NY, USA). Data are presented as the mean \pm standard deviation of $\geq 3$ replicate experiments. $\mathrm{P}<0.05$ was considered to indicate a statistically significant difference.

\section{Results}

P-gp and MRPI expression analysis. The present study analyzed the expression of multidrug resistance proteins $\mathrm{P}-\mathrm{gp}$ and MRP1 in human CML K562 cells and in K562/DOX cells, a K562 subline resistant to doxorubicin. Fluorocytometric analysis confirmed that K562/DOX cells exhibited significant expression of P-gp, compared with the parental K562 cell line (74.9 vs. 6.2\%; Fig. 1A and B). The expression of P-gp in K562/DOX cells was confirmed using western blot analysis, whereby a $180-\mathrm{kDa}$ band in the K562/DOX cells was demonstrated with anti-P-gp antibody (Fig. 1C). The percentage of cells expressing MRP1 was 5.8\% in parental K562 cells, and $13.8 \%$ in K562/DOX cells (Fig. 1D and E).
Rho-123 efflux assay. Rho-123 assay was used to investigate $\mathrm{P}-\mathrm{gp}$ active efflux in parental K562 and K562/DOX cells. The results of the Rho-123 accumulation and efflux assay, used to determine the number of cells with low levels of Rho-123, were based on the extent of efflux that was blocked by the P-gp inhibitor verapamil. As revealed by Fig. 2A, drug-resistant K562/DOX cells demonstrated a significantly reduced accumulation of Rho-123, compared with parental K562 cells (Fig. 2B). Verapamil clearly attenuated the activity of P-gp, which lead to a clear increase in the accumulation of Rho-123 in K562/DOX cells. K562 cells exhibited no significant efflux differences with verapamil.

CD38 expression. A phenotypic analysis of K562 and K562/DOX cells to evaluate the expression of CD38 was performed using flow cytometry. As revealed by Fig. 3A and B, the expression levels of CD38 were 3.2 and $54.1 \%$ in the K562 and K562/DOX cells, respectively. Western blotting analysis using the anti-CD38 antibody demonstrated the presence of a 45-kDa protein in the K562/DOX cells (Fig. 3C).

ADP-ribosyl cyclase activity assays. To investigate endogenous cADPR formation, a spectrophotometric assay of GDPR-cyclase activity in K562 and K562/DOX cells was performed (Fig. 4). This method is based on the conversion of $\mathrm{NGD}^{+}$by ADPR cyclases into a cyclic derivative termed cGDPR, which is resistant to hydrolysis. cGDPR production 
A

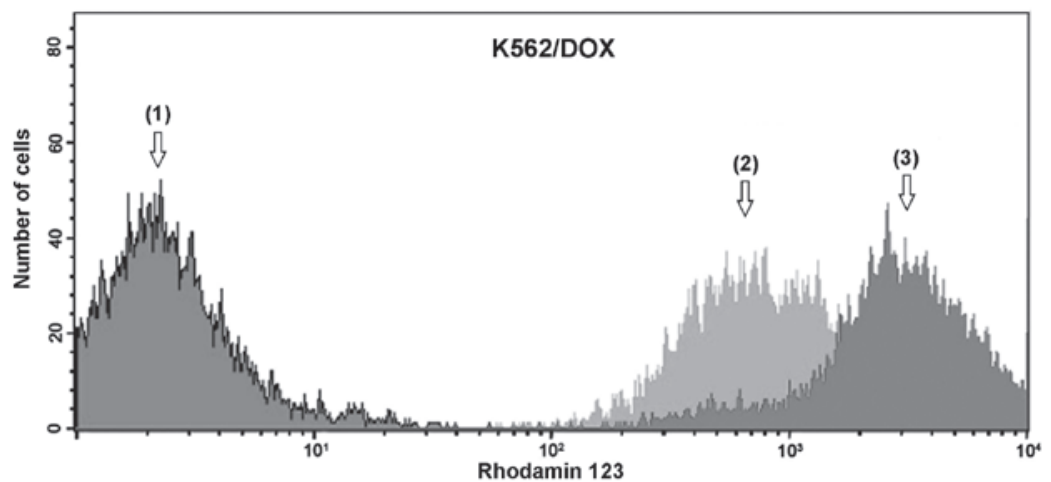

B

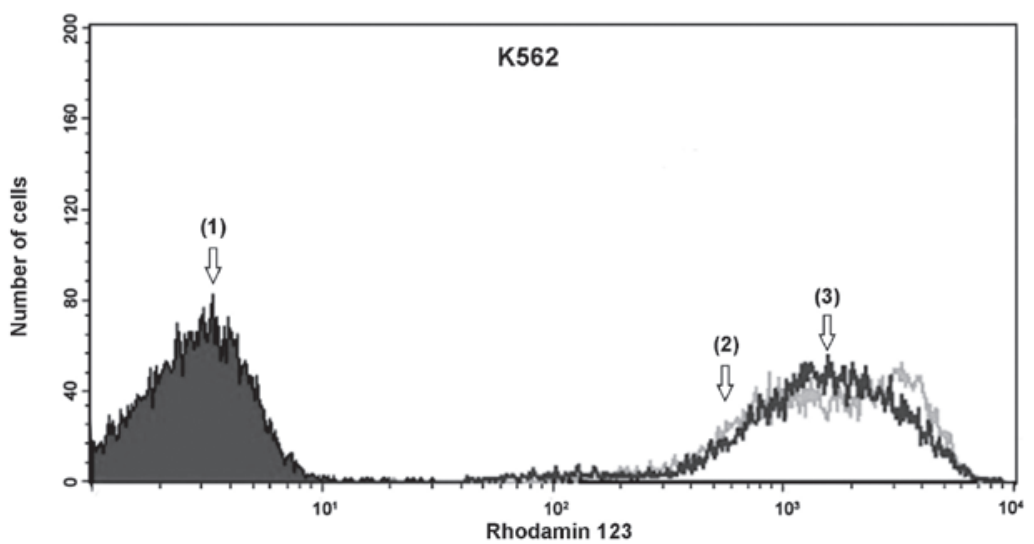

Figure 2. Representative results of Rho-123 accumulation in human chronic myelogenous leukemia (A) K562 and (B) K562/DOX cells. Peaks 1, 2 and 3 correspond to auto-fluorescence of cells without Rho-123, cells incubated with $2 \mu \mathrm{g} / \mathrm{ml} \mathrm{Rho-123}$, and cells incubated with $2 \mu \mathrm{g} / \mathrm{ml}$ Rho- 123 and $20 \mu \mathrm{M}$ verapamil, respectively. Rho-123, rhodamine 123; K562/DOX, human chronic myelogenous leukemia K562 doxorubicin-resistant subline.
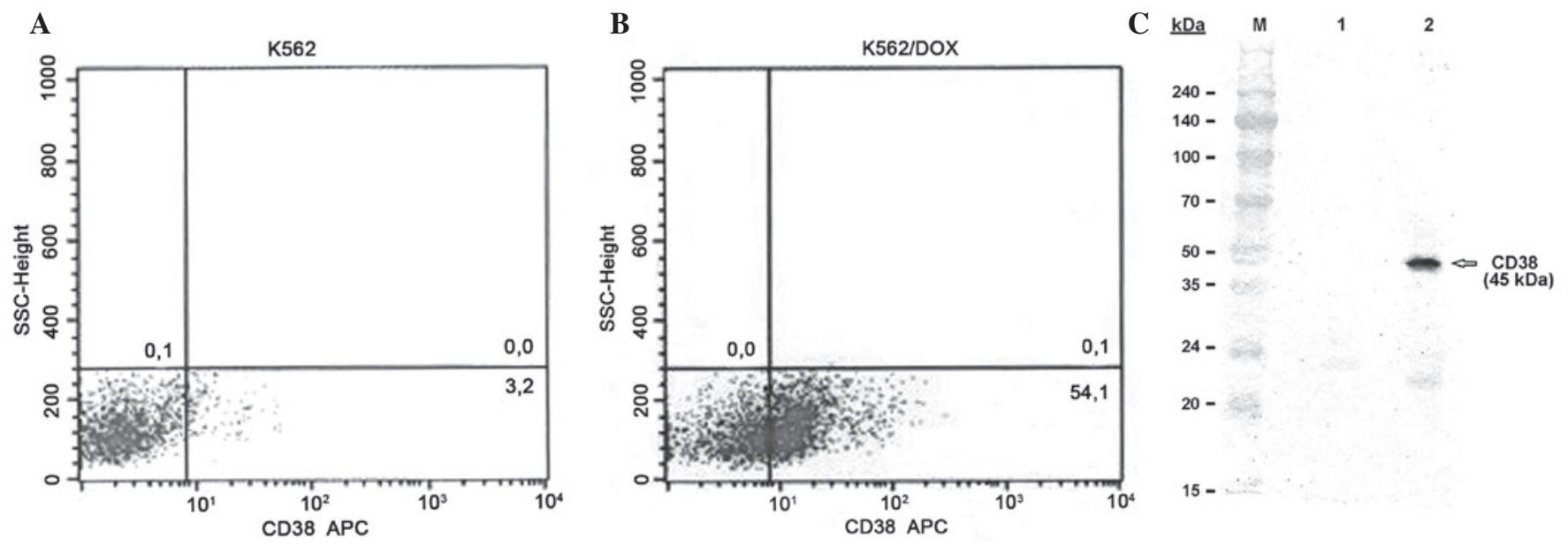

Figure 3. Expression of CD38 in human chronic myelogenous leukemia (A) K562 and (B) K562/DOX cells. (C) Western blot analysis of CD38 in cell lysate proteins from K562 (Lane 1) and K562/DOX (Lane 2) cells. The results presented are representative of 3 experiments. CD, cluster of differentiation; K562/DOX, human chronic myelogenous leukemia K562 doxorubicin-resistant subline; SSC, side-scattered light; APC, allophycocyanin.

was $25.48 \mathrm{nM} / 1 \times 10^{6}$ in K562/DOX cells, which was significantly higher compared with control cells $(\mathrm{P}<0.01)$. No cGDPR activity was observed in the parental K562 cells.

$\mathrm{Ca}^{+2}$ release. Several studies have demonstrated that altered intracellular $\mathrm{Ca}^{+2}$ homeostasis contributes to anticancer drug resistance $(18,19)$. CD38 generates and degrades the second messenger cADPR, and is key in the regulation of transient changes in the intracellular concentration of $\mathrm{Ca}^{2+}(27)$. To investigate the possible involvement of CD38 on $\mathrm{Ca}^{2+}$ metabolism in K562/DOX cells, Fura-2 AM was added to the cells. K562/DOX cells responded rapidly to cADPR (Fig. 5A), and 8-bromo-cADPR (an antagonist of cADPR) blocked the cADPR-mediated release of $\mathrm{Ca}^{2+}$ (Fig. 5B). The effect of verapamil and MK-571 on the cADPR-mediated release of $\mathrm{Ca}^{2+}$ was also investigated in the present study. It was demonstrated that verapamil (Fig. 5C) and MK-571 (Fig. 5D) failed to inhibit the response to cADPR. Thapsigargin is an inhibitor of the sarco/endoplasmic reticulum $\mathrm{Ca}^{2+}$ ATPase (28). Thapsigargin induces the mobilization of intracellular $\mathrm{Ca}^{2+}$ and the depletion 


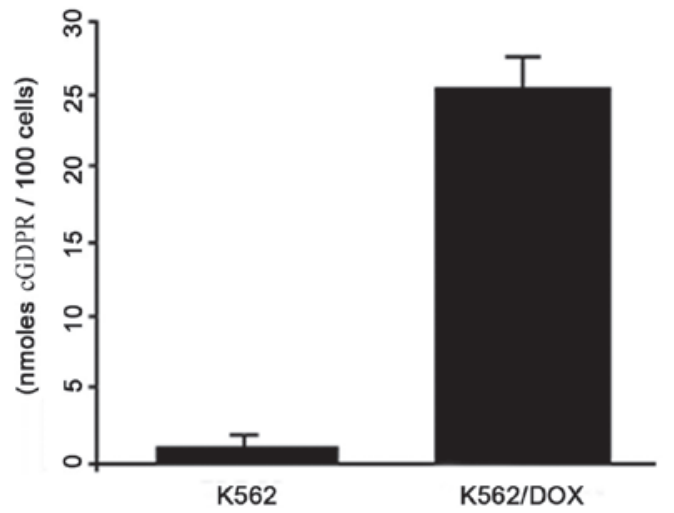

Figure 4. Fluorometric assay of GDP-ribosyl cyclase activity. Human chronic myelogenous leukemia K562 and K562/DOX cells ( $5 \times 10^{6}$ cells) were incubated with $50 \mu \mathrm{M}$ nicotinamide guanine dinucleotide for $1 \mathrm{~h}$, and the fluorescence of cGDPR, the product of the enzymatic reaction, was monitored. The fluorescence intensity of the samples was converted to cGDPR concentration by comparison with cGDPR standards. K562/DOX, human chronic myelogenous leukemia K562 doxorubicin-resistant subline; GDP, guanosine diphosphate; cGDPR, cyclic GDP-ribose.

of $\mathrm{Ca}^{2+}$ from the sarco/endoplasmic reticulum, which is an important intracellular $\mathrm{Ca}^{2+}$ store (29). Thapsigargin has been demonstrated to be a P-gp substrate; therefore, thapsigargin may be eliminated from the cytoplasm in P-gp ${ }^{+}$cells (30). To confirm this, the present study compared the effect of thapsigargin on K562/DOX and K562 cells. The results revealed that K562/DOX cells were more resistant to thapsigargin than K562 cells (Fig. 5E). Therefore, the expression of P-gp in cells may cause resistance to thapsigargin.

\section{Discussion}

Multidrug resistance to anticancer drugs remains one of the most serious challenges for anticancer therapy, and is mainly responsible for the failure of cancer chemotherapy (3). Multidrug ABC transporters, including P-gp and MRP1, are important in the efflux of drugs from tumor cells. Thus, overexpression of $\mathrm{ABC}$ transporters may result in the failure of anticancer chemotherapy (2-4). Overexpression of P-gp, which is an integral membrane protein, represents one of the major mechanisms contributing to the development of the multidrug resistance phenotype, and leads to increased drug efflux (2). However, drug resistance in various cancer cells overexpressing P-gp is not completely reversed by specific inhibitors or gene-specific small interfering RNA, which suggests that there may be additional mechanisms that lead to the development of the multidrug resistance phenotype (31).

In the present study, human CML K562 cells were rendered resistant to the cytotoxicity of doxorubicin by progressive adaptation of the sensitive parental K562 cells to doxorubicin. The resulting subline was termed K652/DOX. The present study investigated the expression of P-gp in K562 and K562/DOX cells. K562/DOX cells exhibited clear $\mathrm{P}$-gp protein levels in western blot analysis, and clear P-gp activity was observed using flow cytometry. By contrast, in the parental K562 cells P-gp was not observed. P-gp activity is measured by the efflux of Rho- 123 , and is inhibited by verapamil. The results of the Rho-123 assay, based on the extent
A

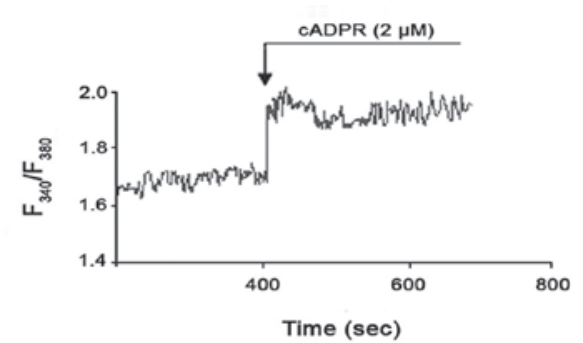

B

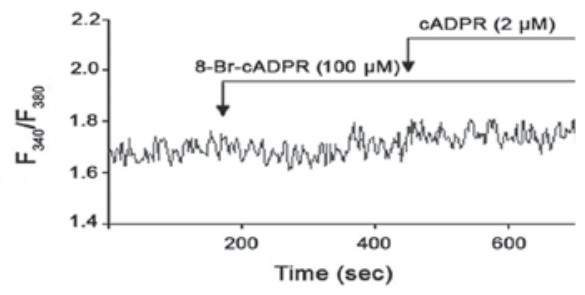

C

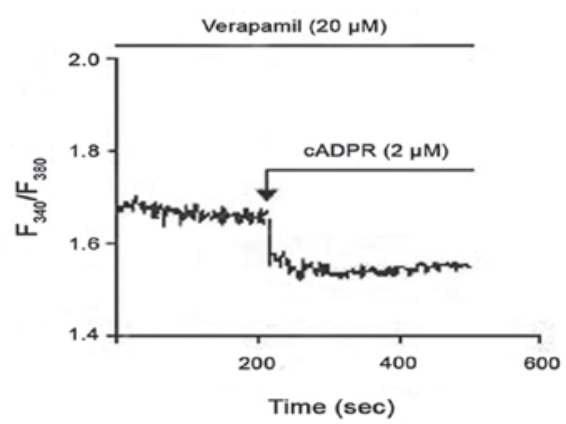

D

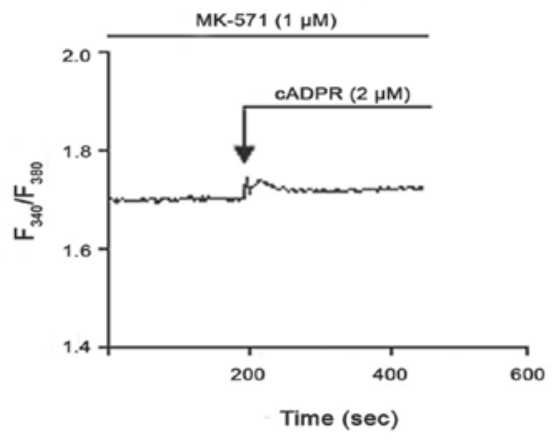

E

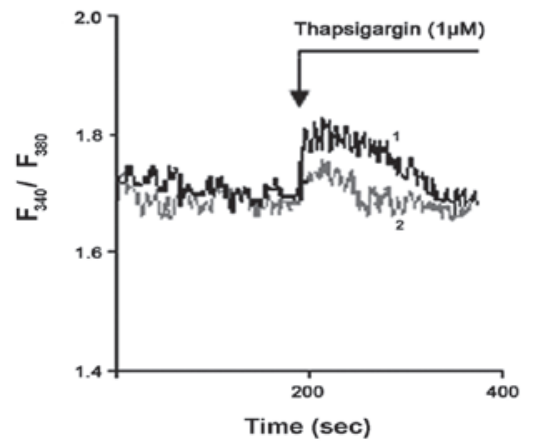

Figure 5. Effect of cADPR on K562/DOX cells. K562/DOX cells were incubated with $5 \mu \mathrm{M}$ Fura-2 acetoxymethyl ester. (A) cADPR $(2 \mu \mathrm{M})$ induced a remarkable $\mathrm{Ca}^{2+}$ release in the absence of extracellular $\mathrm{Ca}^{2+}$. (B) Pretreatment of the cells with $100 \mu \mathrm{M} 8$-bromo-cADPR completely abolished the response of the cells to a subsequent addition of $2 \mu \mathrm{M}$ cADPR. Results are representative of 4 experiments. Pretreatment of the cells with (C) verapamil and (D) MK-571 failed to inhibit the effect of cADPR. (E) Thapsigargin-dependent release of $\mathrm{Ca}^{2+}$ in K562/DOX (1) and K562 (2) cells. The cells were administered $1 \mu \mathrm{M}$ thapsigargin (as indicated by the arrow) in $\mathrm{Ca}^{2+}$-free standard saline. Results are representative of 3 experiments. cADPR, cyclic adenosine diphosphate ribose; K562/DOX, human chronic myelogenous leukemia K562 doxorubicin-resistant subline; 8-Br-cADPR, 8-bromo-cADPR; $\mathrm{Ca}^{2+}$, calcium; F fluorescence intensity. 
of Rho-123 efflux that verapamil was capable of inhibiting, indicated that the differences observed in the fluorescence intensity of Rho-123 were due to P-gp activity in K562 and K562/DOX cells.

The present study revealed that K562/DOX cells expressed CD38 and exhibited ADP-ribosyl cyclase enzymatic activity. The expression levels of CD38 in K562/DOX cells was 54\%, and western blot analysis clearly demonstrated the presence of a $45-\mathrm{kDa}$ band in the K562/DOX cell lysate, but not in the parental K562 cell lysate. To the best of our knowledge, the present study is the first to report direct CD38 involvement in tumor cell drug resistance. CD38 is a single-chain type II transmembrane glycoprotein that is expressed by a variety of hematological cells, and its expression is dependent on cell activation and differentiation (32). In addition to its role as a cell surface marker, CD38 is a multifunctional enzyme that synthesizes cADPR, which is a second messenger (14-17). cADPR is an endogenous $\mathrm{Ca}^{2+}$ mobilizing cyclic nucleoside that targets the stores of $\mathrm{Ca}^{2+}$ located in the endoplasmic reticulum of numerous types of cells and species, including protozoa, plants, animals and humans $(17,33)$. To investigate the role of CD38 in $\mathrm{Ca}^{2+}$ homeostasis and drug resistance, the present study observed the effect of cADPR on Fura-2 AM-loaded cells. The results demonstrated that cADPR led to an increase in intracellular $\mathrm{Ca}^{2+}$, and this effect was inhibited by pre-incubation of the cells with the cADPR antagonist 8-bromo-cADPR. In addition, the present study demonstrated that verapamil and MK-571 did not inhibit the effect of cADPR.

CD38 has been identified as a major cellular NADase that appears to regulate the activity of silent mating type information regulation 2 homolog 1 (SIRT1) and the cellular levels of NAD, which is a key molecule in energy production and signal transduction, two processes that undergo crucial alterations in tumor cells (34). Furthermore, previous evidence indicates that the mammalian stress response gene SIRT1 regulates multiple aspects of cancer drug resistance (35). Chu et al (36) and Oh et al (37) reported that SIRT1 is activated in multiple drug-resistant cancer cell lines and tumor biopsies. The activation of SIRT1 increases the expression of P-gp (35). Therefore, the increase in the expression of ABC transporters induced by SIRT1 may increase drug efflux from cells, which may lead to a decrease in drug concentration in tumor cells and may result in drug resistance. There is no direct evidence to indicate that an induction of CD38 expression in K562/DOX cells and the presence of ADP-ribosyl cyclase enzymatic activity are regulated through SIRT1 (38). Additional studies are required to establish the mechanisms involved.

In conclusion, the present study demonstrated that CD38 participates in the mechanism of drug resistance to chemotherapy, and the present findings may contribute to future studies aimed to identify a molecular basis for the reversal of chemotherapeutic drug resistance in cancer cells.

\section{Acknowledgements}

The present study was supported by the Scientific Research Projects Coordination Unit of Istanbul University (Istanbul, Turkey; project no. 3124).

\section{References}

1. Housman G, Byler S, Heerboth S, Lapinska K, Longacre M, Snyder N and Sarkar S. Drug Resistance in Cancer: An overview. Cancers (Basel) 6: 1769-1792, 2014.

2. Kovalev AA, Tsvetaeva DA and Grudinskaja TV: Role of ABC-cassette transporters (MDR1, MRP1, BCRP) in the development of primary and acquired multiple drug resistance in patients with early and metastatic breast cancer. Exp Oncol 35: 287-290, 2013.

3. Gottesman MM, Fojo T and Bates SE: Multidrug resistance in cancer: Role of ATP-dependent transporters. Nat Rev Cancer 2: 48-58, 2002.

4. Higgins CF: Multiple molecular mechanisms for multidrug resistance transporters. Nature 446: 749-757, 2007.

5. Nooter K, Brutel de la Riviere G, Look MP, van Wingerden KE, Henzen-Logmans SC, Scheper RJ, Flens MJ, Klijn JG, Stoter G and Foekens JA: The prognostic significance of expression of the multidrug resistance-associated protein (MRP) in primary breast cancer. Br J Cancer 76: 486-493, 1997.

6. Juranka PF, Zastawny RL and Ling V: P-glycoprotein: Multidrug-resistance and a superfamily of membrane-associated transport proteins. FASEB J 3: 2583-2592, 1989.

7. Malavasi F, Funaro A, Roggero S, Horenstein A, Calosso L and Mehta K: Human CD38: A glycoprotein in search of a function. Immunol Today 15: 95-97, 1994.

8. Jackson DG and Bell JI: Isolation of a cDNA encoding the human CD38 (T10) molecule, a cell surface glycoprotein with an unusual discontinuous pattern of expression during lymphocyte differentiation. J Immunol 144: 2811-2815, 1990.

9. Summerhill RJ, Jackson DG and Galione A: Human lymphocyte antigen CD38 catalyzes the production of cyclic ADP-ribose. FEBS Lett 335: 231-233, 1993.

10. Zocchi E, Franco L, Guida L, Benatti U, Bargellesi A, Malavasi F, Lee HC and De Flora A: A single protein immunologically identified as CD38 displays $\mathrm{NAD}^{+}$glycohydrolase ADP-ribosyl cyclase and cyclic ADP-ribose hydrolase activities at the outer surface of human erythrocytes. Biochem Biophys Res Commun 196: 1459-1465, 1993.

11. Howard M, Grimaldi JC, Bazan JF, Lund FE, Santos-Argumedo L, Parkhouse RM, Walseth TF and Lee HC: Formation and hydrolysis of cyclic ADP-ribose catalyzed by lymphocyte antigen CD38. Science 262: 1056-1059, 1993.

12. Takasawa S, Tohgo A, Noguchi N, Koguma T, Nata K, Sugimoto T, Yonekura $\mathrm{H}$ and Okamoto $\mathrm{H}$ : Synthesis and hydrolysis of cyclic ADP-ribose by human leukocyte antigen CD38 and inhibition of the hydrolysis by ATP. J Biol Chem 268: 26052-26054, 1993

13. Inageda K, Takahashi K, Tokita K, Nishina H, Kanaho Y, Kukimoto I, Kontani K, Hoshino S and Katada T: Enzyme properties of Aplysia ADP-ribosyl cyclase: Comparison with NAD glycohydrolase of CD38 antigen. J Biochem 117: 125-131, 1995.

14. Galione $\mathrm{A}: \mathrm{Ca}^{(2+)}$-induced $\mathrm{Ca}^{2+}$ release and its modulation by cyclic ADP-ribose. Trends Pharmacol Sci 13: 304-306, 1992.

15. Lee HC: Cyclic ADP-ribose: A new member of a super family of signalling cyclic nucleotides. Cell Signal 6: 591-600, 1994.

16. Aarhus R, Graeff RM, Dickey DM, Walseth TF and Lee HC: ADP-ribosyl cyclase and CD38 catalyze the synthesis of a calcium-mobilizing metabolite from NADP. J Biol Chem 270: 30327-30333, 1995 .

17. Lee HC: Physiological functions of cyclic ADP-ribose and NAADP as calcium messengers. Annu Rev Pharmacol Toxicol 41: 317-345, 2001.

18. Berridge MJ, Bootman MD and Roderick HL: Calcium signalling: Dynamics, homeostasis and remodelling. Nat Rev Mol Cell Biol 4: 517-529, 2003.

19. Smaili SS, Pereira GJ, Costa MM, Rocha KK, Rodrigues L, do Carmo LG, Hirata H and Hsu YT: The role of calcium stores in apoptosis and autophagy. Curr Mol Med 13: 252-265, 2013.

20. Sulová Z, Seres M, Barancík M, Gibalová L, Uhrík B, Poleková L and Breier A: Does any relationship exist between P-glycoprotein-mediated multidrug resistance and intracellular calcium homeostasis. Gen Physiol Biophys 28: F89-F95, 2009.

21. Florea AM and Büsselberg D: Anti-cancer drugs interfere with intracellular calcium signaling. Neurotoxicology 30: 803-810, 2009.

22. Pétriz J and García-López J: Flow cytometric analysis of P-glycoprotein function using rhodamine 123. Leukemia 11: 1124-1130, 1997. 
23. Graeff RM, Walseth TF, Fryxell K, Branton WD and Lee HC: Enzymatic synthesis and characterizations of cyclic GDP-ribose. A procedure for distinguishing enzymes with ADP-ribosyl cyclase activity. J Biol Chem 269: 30260-30267, 1994.

24. Yalcintepe L, Albeniz I, Adin-Cinar S, Tiryaki D, Bermek E, Graeff RM and Lee HC: Nuclear CD38 in retinoic acid-induced HL-60 cells. Exp Cell Res 303: 14-21, 2005.

25. Laemmli UK: Cleavage of structural proteins during the assembly of the head of bacteriophage T4. Nature 227: 680-685, 1970.

26. Grynkiewicz G, Poenie M and Tsien RY: A new generation of $\mathrm{Ca}^{2+}$ indicators with greatly improved fluorescence properties. J Biol Chem 260: 3440-3450, 1985.

27. Zocchi E, Usai C, Guida L, Franco L, Bruzzone S, Passalacqua M and De Flora A. Ligand-induced internalization of CD38 results in intracellular $\mathrm{Ca} 2+$ mobilization: Role of NAD+ transport across cell membranes. FASEB J 13: 273-283, 1999.

28. Watson WD, Facchina SL, Grimaldi M and Verma A. Sarco-endoplasmic reticulum Ca2+ ATPase (SERCA) inhibitors identify a novel calcium pool in the central nervous system. J Neurochem 87: 30-43, 2003.

29. Chen JS, Agarwal N and Mehta K: Multidrug-resistant MCF-7 breast cancer cells contain deficient intracellular calcium pools. Breast Cancer Res Treat 71: 237-247, 2002.

30. Gutheil JC, Hart SR, Belani CP, Melera PW and Hussain A Alterations in $\mathrm{Ca}^{2+}$ transport ATPase and P-glycoprotein expression can mediate resistance to thapsigargin. J Biol Chem 269: 7976-7981, 1994.

31. Kellner U, Hutchinson L, Seidel A, Lage H, Danks MK, Dietel M and Kaufmann SH: Decreased drug accumulation in a mitoxantrone-resistant gastric carcinoma cell line in the absence of P-glycoprotein. Int J Cancer 71: 817-824, 1997.
32. Dürig J, Naschar M, Schmücker U, Renzing-Köhler K, Hölter T, Hüttmann A and Dührsen U: CD38 expression is an important prognostic marker in chronic lymphocytic leukaemia. Leukemia 16: 30-35, 2002.

33. Guse AH: Regulation of calcium signaling by the second messenger cyclic adenosine diphosphoribose (cADPR). Curr Mol Med 4: 239-248, 2004.

34. Aksoy P, Escande C, White TA, Thompson M, Soares S, Benech JC and Chini EN: Regulation of SIRT 1 mediated NAD dependent deacetylation: A novel role for the multifunctional enzyme CD38. Biochem Biophys Res Commun 349: 353-359, 2006.

35. Wang Z and Chen W: Emerging roles of SIRT1 in cancer drug resistance. Genes Cancer 4: 82-90, 2013.

36. Chu F, Chou PM, Zheng X, Mirkin BL and Rebbaa A: Control of multidrug resistance gene $\mathrm{mdr} 1$ and cancer resistance to chemotherapy by the longevity gene sirt1. Cancer Res 65: 10183-10187, 2005.

37. Oh WK, Cho KB, Hien TT, Kim TH, Kim HS, Dao TT, Han HK, Kwon SM, Ahn SG, Yoon JH, et al: Amurensin G, a potent natural SIRT1 inhibitor, rescues doxorubicin responsiveness via down-regulation of multidrug resistance 1. Mol Pharmacol 78: 855-864, 2010

38. Wang Z, Liu Z, Wu X, Chu S, Wang J, Yuan H, Roth M, Yuan YC, Bhatia R and Chen WY. ATRA-induced cellular differentiation and CD38 expression inhibits acquisition of BCR-ABL mutations for CML acquired resistance. PLoS Genet 10: e1004414, 2014. 